\title{
Forms of support and challenges to developing international-mindedness: a comparative case study within a national and an international school in Turkey
}

\section{Akın Metli, Robin Ann Martin \& Jennie Farber Lane}

To cite this article: Akın Metli, Robin Ann Martin \& Jennie Farber Lane (2018): Forms of support and challenges to developing international-mindedness: a comparative case study within a national and an international school in Turkey, Compare: A Journal of Comparative and International Education, DOI: 10.1080/03057925.2018.1490889

To link to this article: https://doi.org/10.1080/03057925.2018.1490889

Published online: 17 Jul 2018.

Submit your article to this journal एँ

Џll Article views: 75

View Crossmark data ¿ 


\title{
Forms of support and challenges to developing international-mindedness: a comparative case study within a national and an international school in Turkey
}

\author{
Akın Metlia, Robin Ann Martin ${ }^{b}$ and Jennie Farber Lane (iD ${ }^{a}$ \\ ${ }^{\mathrm{a} G r a d u a t e}$ School of Education, Bilkent University, Ankara, Turkey; ${ }^{\mathrm{b}}$ Graduate School of Education, Bilkent \\ University, Ankara, Turkey
}

\begin{abstract}
This paper uses mixed methods to explore perceptions of international-mindedness within two case study schools in Istanbul, Turkey: a national school with mostly Turkish students and an international school with students from many nationalities. Using a conceptual framework developed by an international education programme, the authors critically analyse pillars of internationalmindedness: multilingualism, intercultural understanding, and global engagement. Findings reveal that the national school was striving to overcome limitations of homogeneity, while the international school struggled to address its assumptions that a heterogeneous population alone would be enough to encourage intercultural understanding. Neither school had developed clear conceptual links among multilingualism, intercultural understanding, and global engagement. Thus, deliberate efforts are needed to provide students with experiences that foster international-mindedness. Other researchers and educators can use this framework and associated methods to examine how international-mindedness is implemented in different schools in other regions of the world.
\end{abstract}

\section{KEYWORDS}

global engagement; intercultural understanding; international education; international-mindedness; multilingualism

\section{Introduction}

The concept of international mindedness (IM) is a contested one in international education, especially regarding what it includes and how it is lived and practiced in different school contexts (Sriprakash, Singh, and Jing 2014). Marshall (2007) points out that definitions and understandings of terms such as global education, global awareness, and global competence are also debated, including if and how they are similar to IM. Global citizenship, especially, is often used interchangeably with IM (Hicks 2003). One international education programme, the International Baccalaureate (IB) Organization, in particular advocates for use of the word 'mind' when promoting global citizenry:

The difference is not merely semantics: the term 'mindedness' is very important in defining the IB learner's approach. Mindedness is about having empathy, not just knowledge. It is not something that is taught in any particular class; instead it is so embedded in the way an IB student learns that it becomes part of his/her consciousness. (IB World, 2008, 1) 
While how to label IM may be debated, the importance of its inclusion in the curriculum is supported by educators and researchers worldwide (Hansen 2011; Hicks 2003; Skelton et al. 2002). As an international education programme, IB schools educate students to be global leaders who have insights into cultures across the world and care about the wellbeing of others. Therefore, IB schools are ideally positioned for educating students to develop IM by reducing ethnocentrism, increasing intercultural understanding, and promoting global awareness (Schweisfurth 2006).

In 2013, the IB Organization commissioned a study on the conceptualisation and assessment of IM. This report, developed by Singh and Qi (2013), makes an attempt to clarify and define the concept of IM; they also explored how it can be assessed. Their report is based on a systematic analysis of official IB documents, a comprehensive literature review, and a synthesis of contemporary theories, components, issues, and tools in the field. In their study, Singh and Qi established the following three pillars of IM: multilingualism, intercultural understanding, and global engagement.

The current study uses these pillars as a conceptual framework to gain insights into student and teacher perceptions of forms of support for and challenges to IM. Two different school types provide the context for the study: a mono-cultural (with mostly Turkish students) national school compared to a multicultural international school, both located in Istanbul. The research critically explores practices used within these schools to foster IM. By learning about perceptions and practices, the study sought to reveal patterns across the two distinct cases that may help to uncover how the pillars of IM are similarly or differently interpreted, implemented, and critiqued.

\section{Literature review}

Upon reviewing related literature in the field of international education, the authors found that there are limited studies on what schools are doing in practice toward the development of IM. There have, however, been studies that have conducted literature reviews to gain insights into conceptualisations, reflective interpretations, and assessment of IM (e.g. Bailey and Harwood 2012, 2013; Castro, Lundgren, and Woodin 2015; Singh and Qi 2013; Sriprakash, Singh, and Jing 2014). These studies provide valuable background about and insights into understanding IM, especially as it is endorsed through the IB.

While studies related to IM practice are limited, there are a number of researchers who provide recommendations for effective implementation. Sriprakash, Singh, and Jing (2014) state that to integrate school policy and practice, schools need to have an international mind-set in their long-term strategic planning. It is important to explicitly link school events to IM, thereby engaging the critical and creative capacity of students. Similarly, Skelton et al. (2002) and Hacking et al. (2017) support that IM can be promoted effectively when it is interwoven in the standards, curriculum, ethos, and commitment of the school.

Hansen (2011) emphasises that it is the responsibility of schools to raise students' awareness of global perspectives and to develop an appreciation of other points of view. Schools often achieve this through activities such as Model United Nations, Global Issues Network, European Youth Parliament and so on to promote IM. Bunnell, Fertig, 
and James (2017) explain that such extracurricular activities 'relate directly to the institutional primary task of providing an international curriculum' (311). Other than internationalising the school, Akin, Calik, and Engin-Demir (2017) suggest that 'active participation of students in solving the community problems ... would also contribute to the development of in-school democracy, which is crucial in developing the competencies for active citizenship' (827-828).

Another challenge to IM is assessment. Swetz and Swetz (2014) provide signposts to ensure that IM is implemented effectively to:

(1) ask what IM students are capable of doing, not how internationally-minded they are,

(2) embrace open-ended ongoing reflections about IM,

(3) make global culturalism demonstrable through the curricular practices of the school.

Regarding research related to IB and IM, Hill (2012) explains that IM was included as a curricular goal for the IB in the 1960s when it was included in their high school Diploma Programme (DP). Over the years, IB's definition of IM has changed. It began by focusing on intercultural understanding and during the past decade, as a result of the study by Singh and Qi (2013), was expanded to incorporate global engagement and multilingualism. Intercultural understanding is central to the IB understanding of IM, while global engagement and multilingualism are contributors.

With their literature review, Castro, Lundgren, and Woodin (2015) further elaborated on these same three pillars of IM. They noted that a key component of IB is to develop specific learner profiles. While these profiles may be interpreted differently by schools from different cultures, IB emphasises that IM is 'one of the underpinning attributes of its learner profile' (187). Their study concluded that the pillars should be investigated in practice rather than just conceptually to better understand if and how they support IM.

Other studies around the world have explored IB and IM, but did not use the pillars as a conceptual framework; they were mainly comparing students in IBDP to other programmes. In the USA, Hinrichs (2003) surveyed IBPD and Advanced Placement (AP) students and found that the IBDP students had a greater international understanding than AP students. It seems that other studies, however, have found that IBDP was no better than other programmes at supporting IM. Tarc and Beatty's (2012) study, conducted in Canada, revealed that 'students didn't view the aim of international mindedness as being realised' (359). Beek (2017) compared the contextual interpretations of IM of students from a national school and an international school in the Czech Republic. Statistical analysis of the results revealed no significant difference between participants. In her literature review, she reported that other studies conducted around the world (e.g., Qatar and the USA) had similar results. The current study also compares a national to an international school to provide a comprehensive overview of conceptions and practices of IM. This investigation takes place in Turkey and, differently from Beek's (2017) study, uses the pillars of IM as identified by Singh and Qi (2013). 


\section{Methodology}

\section{Research design and context}

The current study is a multi-case research that used mixed methods to explore and explain the phenomenon under investigation (Yin 2003). The authors used a conceptual framework to descriptively analyse the quantitative and qualitative data.

The research engaged students, teachers, and administrators as participants from two case schools: a national and an international school in Istanbul, Turkey. For purposes of anonymity, one school is called National School and the other is International School. As the research involved participants under the age of 18, the researchers acquired formal permission from the Turkish Ministry of Education and informed consent from participants. The anonymity of participants was maintained during the analysis and reporting.

Both schools are co-educational private schools authorised to implement IB's Primary Years Programme, Middle Years Programme, and Diploma Programme. The case schools were invited to this research because they had been implementing IB for over 10 years and have the longest running implementation of all three IB programmes in Turkey.

\section{Instrumentation}

\section{Qualitative instruments}

The qualitative instruments for the study were based on semi-structured interviews, focus groups, and school culture observations. The interview and focus-group protocols and questions were prepared based on the stages of an interview investigation and the areas of investigation (Brinkman and Kvale 2015). Interview and focus-group questions explored topics related to IM such as curricular and extracurricular activities, procedures and policies, forms of support, and challenges for students and teachers. Questions asked in both the interviews and focus groups are:

- How would you define IM?

- How important do you think IM is at your school?

- What does multilingualism/intercultural understanding/global engagement mean to you? (one question for each) Does your school develop students' multilingualism/ intercultural understanding/global engagement? If yes, how does it support students in terms of developing their multilingualism/intercultural understanding/global engagement? Can you give any examples and evidence to illustrate your points?

- What other learning opportunities does your school provide to accomplish intercultural goals and address intercultural issues?

- How would you describe the impact of the DP core components (CAS(Creativity, Activity, Service), Theory of Knowledge, EE) in terms of the development of internationally-minded individuals?

- What are the current challenges of the implementation of IM in your school? How are you addressing the challenges?

- How would you describe the impact of IBDP on students in terms of developing internationally-minded individuals? 
School observations were also conducted using an unobtrusive ethnographic approach throughout one day in each school. An audit form for describing the school environment was adapted from Hacking et al. (2017). Notes were taken about bulletin boards, displays, and other common spaces to record evidence about artefacts that showed each school's lived ethos, aims, communications, diversity, and viewpoints in terms of their global or local perspectives.

\section{Quantitative instruments}

For collecting demographic data, a general survey was derived from two exploratory surveys developed by Özakman (2017) and Yazgan (2017), and used with permission. The survey included both student and teacher forms, each included questions about multilingualism and experiences in other cultures.

The other quantitative instruments were the Intercultural Development Inventory (IDI) and the Global Citizenship Scale (GCS) surveys. The IDI was used to identify students' levels of intercultural understanding. The IDI was conceptualised from Bennett's (2004) Developmental Model of Intercultural Sensitivity. The IDI testing agency uses five stages of development to assess individuals in terms of their perceived and developmental scores of intercultural understanding: denial, polarisation, minimisation, acceptance, and adaptation (Bennett 2004). The IDI is based on a cross cultural sample of 591 culturally diverse respondents (Hammer, Bennett, and Wiseman 2003). As a theoretically grounded measure, it possesses strong content and construct validity across cultures and has been shown to be statistically reliable (Paige et al. 2003).

The Global Citizenship Scale (GCS) (Morais and Ogden 2010) was used to identify students' levels of global engagement. It is a theoretically grounded and empirically validated scale that measures global citizenship encompassing the three dimensions (and sub-dimensions) of social responsibility, global competence, and global civic engagement.

\section{Piloting the study}

Both of the qualitative and quantitative instruments were piloted at an IBDP school in eastern Turkey. It was chosen as the pilot school because of its ease of access and convenience in terms of time, resources, and budget. The lead author had worked at this school for 10 years and to avoid researcher bias, was not chosen as one of the main case study schools. Three online surveys (the Demographic Information Survey, the Intercultural Development Inventory, and the Global Citizenship Survey) were completed by 33 grade 11 students at the pilot school. Four interviews (core curricula coordinators, teachers, and administrator) and six focus groups (students and teachers) were recorded with permission. The pilot results were used to inform the effectiveness of the overall research design and to improve data collection methods. Based on the feedback, the researchers simplified the language of the GCS, especially for non-native speakers of English, allocated more time for administering the instruments. The interview and focus-group questions were revised to improve their clarity and to align better with items in the GCS and IDI. 


\section{Sampling}

For the actual study, the sample population for the questionnaires were grade 11 students: 41 students from the International School and 33 from the National School. The research used nonprobability purposeful sampling to select a targeted group of students and their teachers at the two participating case study schools. Focus-group discussions were conducted with four-to-six students from grades 11 and 12 in each school; they represented a blend of males and females from different social backgrounds and ethnic groups. Focus-group discussions were also conducted with three-to-five teachers from DP core components (Creativity, Activity, Service; Theory of Knowledge; Extended Essay) representing various subjects such as languages, humanities, sciences, and mathematics.

\section{Data collection}

The data collection was carried out during three separate two-day visits to each case school in the fall and spring terms of 2016-2017. The demographic information survey, the IDI, and the GCS surveys were administered during the first visit. During this visit, the semi-structured interviews with the coordinators and school administrators were conducted as well. The second visit included focus-group discussions with students and with teachers. Nine interviews (with core curricula coordinators, teachers, and administrators) and 12 focus groups (with students and teachers) were recorded with permission. They were transcribed in preparation for content analysis using the data coding software Nvivo 11 Pro. The last visit focused on observations of the school environment.

\section{Data analysis}

\section{Qualitative data analysis}

This study used thematic content analysis (Braun and Clarke 2006) in which the researchers looked for common themes and differences across stakeholders. Researchers created the following scheme of work based on the common themes arising from the transcripts as well as from notes taken during school culture observations:

(1) perceived meanings, definitions, significance of IM,

(2) curricular and non-curricular examples/practices of IM,

(3) forms of support/challenges for students and teachers relating to IM.

The two lead authors developed codes and sub-codes for the above themes after intensive discussions to cross-code the transcripts and school culture observation notes. Consensus was reached by carefully reviewing the merged projects to identify any conceptual disagreements and looking for common themes and points of difference. The data analysis was linked conceptually with the quantitative measures, IDI and GCS. After the initial analysis of the codes, the researchers prepared customised school profiles for both schools and sent them to schools for member checking. 


\section{The quantitative data analysis}

The quantitative data were mainly derived from the GCS and IDI scales. The IDI school profiles were created by the IDI Company (2017). The IDI Company measured the level of intercultural competence/sensitivity across a developmental continuum for individuals' perceived and developmental orientations. The GCS and IDI scores were analysed based on descriptive (means and standard deviations) and inferential statistics (independent sample $t$-tests) for school comparisons. All tests were conducted with $a=.05$. The quantitative data provided confirmatory insights and additional descriptors to the qualitative findings.

\section{Results}

\section{Forms of support for, practices of, and challenges to IM}

While both schools showed similar evidence of forms of support for IM within their school cultures, there were notable differences in how each school interpreted and made sense of the evidence. To gain insights into these differences, the sections below explore participants' perceptions of forms of support, practices of, and challenges to IM and its pillars.

\section{Perceived IM: forms of support and practices}

The qualitative analysis revealed that both schools had similar examples of campuswide forms of support for IM, such as their mission, school environment, and extracurricular activities to foster IM. There were, however, more notable instances where IM was more purposefully emphasised within the National School. Furthermore, while similar activities were observed at both schools, the discourse surrounding the critique of those activities varied greatly. The International School participants were more directly critical of their own approach, whereas, the National School participants focused more on the facilitating factors to foster IM.

Regarding the mission statements, the International School's mission describes a challenging curricula and strong student/staff relationships for providing a caring environment 'that inspires' students with respect to the explicit values of being 'inquisitive, creative, compassionate, balanced, and internationally minded'. A similar, but slightly more specific, global perspective is embedded in the mission statement of the National School. It aims to raise 'multilingual, innovative and life-long learning citizens with high ethical and academic standards, who are equipped with social, international and multicultural awareness'. Notably, there was verbiage in the National School's mission that indicates it is striving for IM. The school emphasises 'multicultural and international awareness' and has objectives focused on multilingualism, such as to 'use one's mother tongue and English at the best possible proficiency, improve the use of foreign languages at the best possible communicative level'.

As far as how IM is reflected in the school environment, the researcher noted IMrelated practices on display boards more in the International School than the National School. Community service projects that lead to global engagement as well as intercultural understanding were evident at both schools. The International School exhibited an art project about 'celebrating diversity'. Images expressing the importance of praying 
and providing information about Islam and the Quran were posted alongside artwork from other countries, including a US culture reinterpretation of McDonalds. Historic cultures were also represented through a Turkish literature project of the mysteries of Göbekli Tepe. In contrast, examples of displays around the National School campus were not quite focused on international perspectives because they were more 'celebrating nationalistic views'. For example, the school displayed a wide range of student products that mainly depicted artefacts of Turkish culture. It was also evident that the school paid attention to displays related to nationalistic views including posters about Turkish civilizations, Atatürk's principles and reforms, and important days in Turkish history (e.g. Çanakkale Victory Day). Although other cultures were not represented explicitly, there were images expressing the ideals of IM. These included displays about raising awareness of global issues such as racial discrimination, protecting the environment, and building peace.

At the International School, the most commonly used activities to develop student IM or 'intercultural awareness' were activities such as Model United Nations, sports, theatre productions, and International Day. While admitting that International Days tended toward superficial activities related to IM, one teacher noted that some activities that appeared to be 'fun and games' were actually quite successful for promoting collaborative discussions among students. These experiences helped create 'a little bit more of a caring community, and understanding, and we know each other and we see each other in a different light ... as human beings, and not just teacher, students'.

Teachers and students at the National School were very positive about their IMrelated activities. They mentioned that attending conferences with other IB schools, such as the international Theory of Knowledge and Model United Nations conferences, European Youth Parliament and Global Issues Network clubs, and cultural trips organised abroad, enabled students to develop their intercultural understanding. Through these exchanges they learned about different cultures and familiarised themselves with different ways of thinking.

Global engagement appeared to have the strongest emphasis at the National School in its wide range of service activities. The following activities were reported to improve students' social responsibility, global civic engagement, and global competence:

(1) teaching origami to visually impaired women,

(2) preparing gift boxes for Syrian refugee children,

(3) buying coats and shoes for needy people living in eastern Turkey,

(4) raising money to buy wheelchairs for the disabled people,

(5) participating in an environmental project (clean water project) in Kumbaba beach, Istanbul,

(6) becoming a Best Buddy to help mentally disabled people to socialise,

(7) raising money for an association for the orthopedically handicapped.

\section{Perceived challenges to school-wide IM practices}

Conceptualising IM was difficult for both schools because it was perceived to be ambiguous and vague. Teachers implied that conceptualising IM was difficult because it is poorly defined. Teachers commented that because of the vague and ambiguous 
understanding of IM, 'it is hard to collect evidence of students' development of IM' or also 'teach it in a short amount of time'.

At both schools, participants mentioned that it was difficult to evaluate and assess IM. They said that the assessment tools provided by the IB did not provide insights into students' IM. At the International School, one student and three teachers shared that they doubted IM is even measurable. The student elaborated:

It's a privilege to be in an international school. It's a privilege to have all of these different cultures surrounding you. But at the same time, I don't think you can understand the cultures without engaging with the cultures. And it's kind of a false sense of understanding ... you can see the [Learner Profile] attributes in how you act, in how you do your schoolwork as compared to IM, which isn't really measurable.

Nonetheless, some teachers pushed their comfort levels and showed openness to questioning assumptions that IM is immeasurable, they were beginning to consider how self-assessment tools for IM might indeed be helpful.

While both schools shared common challenges to fostering IM, the comments shared by students and teachers at the International School were more worrisome and critical. At the International School, both teachers and students struggled to identify curricular forms of support for developing IM. Many students felt they were becoming more internationally-minded simply by being in an international school. Some students explained that in their view, IM is about one's personality and that is developed mostly with one's own efforts. Furthermore, others did not credit the school for fostering IM, saying that it is something aside from the things we do in school. It's something we develop through our surroundings and our friends and who's around us'.

Several school leaders indicated that the international makeup of the school may lead to IM being taken for granted. The DP coordinator admitted the disadvantage of being an international community:

We take it for granted that we are living in an international environment, therefore the students are exposed to international mindedness. Therefore ... that's in our blood, in the air that we breathe. Yes, it is true to a certain extent, but that I think takes us away from doing more concrete things in our lessons or in the curriculum.

Ironically, this diversity presented a unique challenge to fostering IM at the International School. Students considered themselves to be 'third culture kids' representing several cultures, which may have affected their sense of identity. As one teacher explained, 'they don't know who they are'.

An emerging discourse among teachers at the International School revealed a recognition that the curriculum needs to support IM more proactively. Most students and teachers did not perceive the school as having explicit teaching and learning strategies for fostering IM. The idea that IM may need support, and just as other subject areas require scaffolding, is just dawning as a notion at the school.

In contrast, the teachers and students at the National School perceived IM as a process, a quality that develops over time. Both students and teachers emphasised that the development of IM is affected by the school environment and curriculum. Compared to the internal challenges to IM of the International School, the National School had more external challenges: they were Turks in Turkey during a period of increased political restraints and terrorism. Students seemed to be more compelled to discuss national issues. 
One student noted that their religion course does not offer 'the study of other religions', only Islam. Another mentioned that their school policy prohibited conducting some holidays of other cultures, such as Halloween. The recent sociopolitical environment of the country was considered as a barrier because 'when students would like to do projects in the eastern part of Turkey, they are not allowed by their parents because of the recent bombings and terror attacks'. In one case, the external events (an attempted coup) led to the cancellation of the International Theory of Knowledge Conference, which students reported has been especially important for fostering IM.

A less dramatic, yet persistent external influence on the implementation of forms of support for IM was that the National School was required to deliver both the national and IB curriculum simultaneously. Needing to meet the criteria of two distinct programmes meant teachers and students had to overcome barriers such as 'bureaucracy, budget and time issues'; these obstacles especially affected organising and conducting community service projects. Thus, while teachers and students at the National School seemed to recognise that fostering IM benefited from purposeful and planned activities, sometimes their efforts were compromised by external challenges.

\section{Multilingualism}

\section{Indicators of multilingualism}

The International School students come from a wide range of nationalities, thus they speak various foreign languages as a first and second language. Almost all the National School students come from a mono-cultural background and thus speak Turkish as the mother tongue and speak mainly English as a second language.

At the International School, $62.5 \%$ of participating students classified their ethnic background as Caucasian/White, $17.5 \%$ as Asian, the remainder as Latino, Middle Eastern/Arab, Indian, or North African. Among the students, 44\% $(n=18)$ spoke only English as their native tongue. About the same percentage was multilingual, speaking English along with one-to-three other languages as their native tongue (such as Turkish, Danish, French, Spanish, Russian, or Azeri), and the remaining $12 \%$ had only Turkish or Italian as their native language. Almost all students $(n=40)$ listed their proficiency in at least one other language at a beginning or intermediate level. The languages most frequently listed were Spanish, French, and Turkish and less frequent ones were Russian, Arabic, Portuguese, Chinese, Japanese, and Korean.

In clear contrast, all-but-one of the National School students $(n=33 ; 96.8 \%)$ classified their ethnic background as Turkish. The one non-Turkish student was Latino. Nearly all of the students were studying English as a second language $(n=32$; 96.9\%) at an advanced level. There were four students (3.1\%) who were proficient at another language (Finnish) in addition to English. Almost all the students $(n=32)$ indicated that they were at the beginning or intermediate level in at least one other language besides English. The languages most frequently listed were Spanish, French, German, and less frequent ones were Italian and Korean.

\section{Forms of support for multilingualism}

A bilingual programme and multilingual cultural education were the major school-wide examples of forms of support for multilingualism. Participants from International 
School supported the view that a multilingual culture was helpful for the developing multilingual learners. The comments by participants also uncovered a mutually supportive relationship between multilingualism and global engagement at the International School. For example, service activities that utilise language involved students who were fluent in one language tutoring other students. Likewise, sometimes other community-based activities encouraged students to use their Turkish or other languages in service work.

In contrast, comments about multilingualism in the National School focused more on how the bilingual programme helped to develop students' further interests in other cultures. The participants emphasised that by learning a different language, they gain insights into different ways of thinking and reasoning. These insights facilitate and deepen students' understanding of cultural beliefs and traditions.

\section{Challenges to multilingualism}

At the International School, five of the six subjects in the IB curricula are mostly delivered in English; this emphasis on one language compromised the development of multilingualism. Students lacked opportunities to advance skills in their mother tongue, and immersion in languages besides English was limited.

Teachers and students at the National School also noted the emphasis on English, but this was not perceived to be a barrier to multilingualism. Instead, their issue was time. They are required to follow the national curriculum in addition to IB and do not have time for a third language.

\section{Intercultural understanding}

\section{Measures of students' intercultural understanding}

The Intercultural Development Inventory has two orientations, Perceived and Developmental. The Perceived Orientation indicates where a group as a whole reflects intercultural understanding: Denial, Polarisation (Defence/Reversal), Minimisation, Acceptance, Adaptation (Hammer 2017). The Developmental Orientation points out 'the group's primary orientation towards cultural differences and commonalities along the continuum as assessed by the IDI' (Hammer 2007, 5). Similar to the Perceived Orientation, the Developmental Orientation can be Denial, Polarisation (Defence/ Reversal), Minimisation, Acceptance, Adaptation. Finally, there is the Orientation Gap, which is the difference along the continuum between the Perceived and Developmental Orientation. A gap score of 7 points or higher can be considered a meaningful difference between where the group perceives itself on the developmental continuum and where the IDI places the group's level of intercultural competence.

According to the IDI group profile prepared by the professional IDI company (Hammer 2017), the Perceived Orientation of both the National and International Schools is the same. It indicates that students are at the level of Acceptance for their understanding and appropriately adapting to cultural differences. This rating reflects that students recognise and appreciate differences in values, perceptions, and behaviours among different cultures, including their own. According to the IDI Perceived Orientation, students believed that they possessed a high level of intercultural competence. 
Alternatively, the Developmental Orientation of the National School and the International School is different from each other. The Developmental Orientation of students in the International School is at the Cusp of Minimization stage, while the National School students scored within the Polarisation range. Individuals within the Cusp of Minimization have a slight tendency to highlight commonalities across cultures that can mask important cultural differences in values, perceptions, and behaviours. Polarisation, on the other hand, reflects an 'us and them' judgmental viewpoint toward cultural differences. This stage can take form of Defence or Reversal. For the former different values, perceptions, and behaviours associated with a culturally different group of people tend to be evaluated negatively; values, perceptions, and behaviours of 'my' group are judged more favourably. With Reversal, other cultural practices are less critically evaluated and cultural practices within one's own group are likely to be judged from an overly critical standpoint. In the focus group with students, the researcher noted more examples of the form of Defence than Reversal in students' perceptions related with different cultural practices. For example, the following student shows an overly critical standpoint: 'If you don't tip in America you're a criminal. That's the culture ... I think it's a bad system from an economic perspective but that's the way, how it is.'

Finally, the Orientation Gap between the Perceived Orientation score and the Developmental Orientation score for the National School is 38.07 points and for the International School it is 34.68 points. According to Hammer (2017), a Perceived Orientation score that is 7 or more points higher than the Developmental Orientation score indicates the group has overestimated its level of intercultural competence. A Developmental Orientation that is 7 points or more than the Perceived Orientation score indicates that the group has underestimated its intercultural competence. According to the results, both groups have Perceived Orientation higher than Developmental Orientation, which indicates that they substantially overestimated their levels of intercultural competence.

To further investigate the differences in scores between the two schools, descriptive and inferential analysis were performed. According to the independent sample $t$-test results, the mean of the Developmental Orientations of the IDI scores of the National School students were not found to be significantly different from the International School students $(t(68)=-1.603, p<.05)$. Despite the results not being statistically significantly different, there is a notable difference in terms of the mean of the International School $(M=84.440)$ and the National School $(M=78.805)$. International School students were slightly better at both the perceived and developmental orientations of IDI.

\section{Form of support for intercultural understanding}

Similar non-academic forms of support for intercultural understanding were noted at both schools. For example, in the demographic information survey of 33 students at the National School and of 44 students at the International School:

- Both schools noted how they participated in sports that crossed national boundaries.

- Both schools remarked on their cross-cultural interests such as watching movies, listening to different types of music, dance, language learning, reading different international literary pieces or world news/current issues. 
- Both schools claimed that they liked to travel and take trips for activities such as Model United National and Social Entrepreneurship clubs.

However, students from neither school mentioned how participating in such activities specifically helped them to develop their intercultural understanding.

With regards to academic forms of support at the National School, students claimed that their curriculum is 'based on international perspectives'. Both students and teachers provided examples to show that intercultural understanding can be integrated into any subject area. The course Turkey in the $20^{\text {th }}$ Century helps students to explore international perspectives and to go beyond nationalistic views and feelings. Through their literature courses, students explore other cultures while studying visual, spoken, or written texts from foreign authors. Their foreign language courses helped them explore global issues, such as immigration and globalisation. Even mathematics courses broadened their awareness of different cultures by learning about famous mathematicians from around the world and how different countries express calculations and equations. From the school visits and interviews, it was apparent that emphasis of world views was appreciated by students.

At the International School, the IB curricula were perceived to support the development of students' IM in languages and humanities disciplines. Particularly, languages were seen to link multilingualism and intercultural understanding, while geography supported intercultural understanding. Intercultural understanding was also included culture and language clubs, community projects involving culturally distinct participants, and international cultural fairs and festivals.

Most notably, the differences between the schools regarding their intercultural understanding were embedded in their heterogeneous versus homogenous student populations. School-wide examples of intercultural understanding at the International School underscored qualities of being both a school with a diverse population and within a diverse community. Diversity is inherent in the nature of the school itself and is enhanced with contributions from families that have travelled the world. Participants pointed out that their diversity creates a platform for conversations on current events. Student conversations are often unplanned and organic; they help cultural interactions with one another. Both teachers and students commented upon their diversity issue repeatedly, but it was never clear the extent to which the curriculum or teaching strategies took advantage of this fact. One teacher explained:

We're an international school with 40 some nationalities here .... Kids are very, very cognizant that there's many cultures within the building. That all comes together to create a third culture outside of the national culture here and outside of their own culture, as well.

School-wide examples of intercultural understanding at the National School were heavily dependent upon extracurricular activities such as the international TOK conference or Model United Nations conferences, Global Issues Network, European Space Organization, and European Youth Parliament. Participants claimed that these experiences helped students understand different perspectives of countries, how to approach someone with different perspectives than theirs, and to learn about other ways of thinking by working within cross-cultural groups. For example, one student from the National School talked about the how the TOK conference they organised helped them become 'culturally 
engaged' by reflecting upon a personal experience she had about a group of participants from Jordan. Another CAS student drew attention to the value of these extracurricular activities because he claimed that 'we learn theoretical values of IM but in practice, in face to face we can face our challenges and we can learn actually when it comes to practice'. The DP coordinator also supported the idea that attending conferences helps students get to know people from different cultures and do collaboration, networking, and befriending. For instance, she gave an example conference in which students had intercultural interactions while working with internationals schools on astronomy projects in the European Space Organization: 'The students from other countries is very important because they try to respect the thoughts of other students ....'

\section{Challenges to intercultural understanding}

The intercultural challenges faced by both schools are distinct in that the International School is challenged by the diversity of its own school culture and by the lack of curricular support, whereas the National School is challenged by limited resources. At the International School, there was a general agreement among students, teachers, and administrators that intercultural understanding was not well addressed by the school's curriculum and only tangentially by the school culture. In focus groups and interviews with teachers and coordinators, participants discussed school-wide challenges in relation to how the school culture seemed constrained in fostering IM. Participants gave examples such as the shallowness of the school's International Day, overemphasis on western values (especially British and US), focus on individualism, and lack of sensitivity to students' varying backgrounds. They noted in particular that teachers may not encourage students to share news from their home countries, especially if the news was troubling or divisive. In classrooms, there were not many intercultural dialogues between students from the local culture and other cultures.

The challenges to intercultural understanding at the National School centred on school-based constraints such as having a homogenous environment, which limited opportunities to provide real life examples of cultural differences. Furthermore, although integration of topics and concepts from different countries is supported, the teachers and students from both schools shared that it is more difficult to do so in science and math courses than in the humanities and language courses.

\section{Global engagement}

\section{Measures of students' global engagement}

According to the descriptive and inferential analysis of the GCS and its sub-scales, both National and International School students have similar viewpoints. The independent sample $t$-test results comparing the National School students to International School students revealed no statistically significant difference between these two groups of schools $(t[72]=0.928, p<.05)$. While not statistically different, the mean scores reveal that the National School students $(M=163.52)$ were slightly better than the International School students $(M=150.20)$. These findings were supported by insights gained from qualitative data analysis. 


\section{Forms of support for global engagement}

At both the National and International School, many visual indicators of global engagement were evident. At the International School there were community service projects on 'How to join Ecosia', a refugee outreach programme and a student-run club about raising awareness on the Gay/Straight Alliance. Examples of global engagement were also plentiful at the National School: Equality, justice and freedom project; $21^{\text {st }}$ March Elimination of Racial Discrimination Day celebration; More Peace and More Serenity projects; poster on extinct and endangered animals; and Eco-schools projects related to biodiversity and recycling.

Academic examples of global engagement were also noted in DP courses at the National School and the International School. At the International School, the school principal noted that in DP, the humanities, and art were particularly useful for helping students understand global issues. For example, the art teacher mentioned a group of seniors who were doing projects on identity and the Syrian refugee crisis. At the National School, the English Extended Essay supervisor noted the course was particularly useful for helping students study global issues such as 'immigration, globalisation, global warming'. The DP Coordinator also gave mathematics as an example as it helped students 'predict a model for the future's environmental problem'.

\section{Challenges to global engagement}

Challenges to supporting global engagement varied extensively at both the National and the International School. At the International School, it appeared to relate especially with a few teachers' tendency toward being constructively critical of how the school might improve. These teachers suggested that international school teachers need to develop sensitivity and impartiality in guiding culturally diverse students to openly and politely debate global or local issues that have controversial perspectives. Similarly, coordinators discussed ideas for fostering student empathy, not pity, for other socioeconomic classes during community service projects.

In contrast to looking for ways to improve themselves internally, the challenges to global engagement perceived by participants at the National School were centred on external constraints such as limited extracurricular activity participation. Students mentioned that grade 12 students were not allowed to attend certain trips or activities because of their high IBDP workload at school or their preparations for the national university entrance examinations. Another external constraint was difficulties students face when they propose or carry out community service projects. The DP coordinator pointed out that students may be ignorant of ethical considerations, resist working in groups, and lack motivation to maintain their involvement. Unfortunately, it seems that community involvement projects are seen as extra work that is outside of and may even compromise academic achievement. Thus, this strategy to promote global engagement may be less successful than other endeavours.

\section{Conclusion}

A key outcome of the current study is that it cannot be assumed that students and teachers coming from diverse countries and cultures learning together will naturally lead to IM. The study also confirms what Hacking et al. (2017) found - that developing 
IM is more than the merely adopting an IB programme. Although other studies compared national and international schools and reached similar conclusions (e.g. Beek 2017; Cause 2009), the current study provided more specific findings by using the pillars of IM as a framework and by investigating practices related to IB core components such as Theory of Knowledge, Service projects (Community, Action, Service) and research (Extended Essay).

The framework guided the researchers to select assessment instruments that measured cultural understanding and global engagement. Analysis of the data from these instruments found no significant differences between students from a DP school with a multicultural student body and one that is composed of mainly Turkish students. Qualitative findings from the study indicated that a diverse population could actually deter the development IM because stakeholders may assume no additional effort is needed. This supports the finding that regardless of the student and teacher profile, IM develops through intentional efforts with the help of various pedagogical, curricular, and extracurricular methods.

While not statistically different, it was important to note that the National School had higher mean scores in global engagement and the International School had higher mean scores in intercultural understanding. These results match with the qualitative findings in that the National School had more action-based service projects while the International School had a diverse community that enabled more intercultural communication. Schools with diverse cultures can benefit from the natural and organic international interactions both inside and outside of classrooms. If they are in a cosmopolitan city, they can tap into community-based support such as the expatriate groups to develop students' intercultural awareness.

The study also found that neither school seemed to make direct curricular links in how the three pillars of IM might be mutually supportive of each other. The data collected from the participants did not indicate if there could be a missing pillar or missing conceptual links that could help to better guide students in their development of IM. While insights regarding intercultural understanding and global engagement were shared in interviews and via the instruments, the role of multilingualism was unclear. If multilingualism is approached with greater attention to the language and culture links, could it be a foundation for intercultural understanding? Is it possible for people to have intercultural understanding without knowing a foreign language? Is it possible for people to be globally engaged while still lacking intercultural understanding? The present study did not explore these questions explicitly, but suggests that future studies investigate how the IM pillars may interact to better develop a theory on IM and to improve international curriculum.

The researchers recommend the following implications for practice to deal with the general constraints to developing IM. Firstly, as found in the present study, schools should incorporate intercultural understanding as well as global engagement in both curricular and extracurricular practices to enable students to value their own cultural beliefs and to cultivate a mutual respect among diverse cultures. These practices will help students to be caring and problem solvers for local and global problems. Cause (2009) suggests that students should be guided through 'building classroom cultures, along with the wider school community that fosters ethical and inclusive intercultural relations' (170). Secondly, Skelton et al. (2002) posit that an internationally-minded 
approach to education expects students and teachers to discuss 'the threat of international terrorism, the increasing racially biased political parties, degradation of the environment' (52) and to work toward peace, tolerance, and global cooperation. Therefore, it is important for schools to organise varied activities that raise awareness about identified problems, to develop well-designed community service projects in different languages to reach more people, and to run these projects continuously to address the local or global needs. Lastly, teachers need to be internationally-minded and act as role models. Student-teachers in teacher education departments can be better prepared to promote IM.

Any school, whether it is national, international, public, or private, can utilise these research findings to reflect on the perceptions of forms of support, practices, and challenges of IM. Other schools can also use the framework for evaluating their strategies and policies for developing IM. The outcome of the analysis can be used to develop an action plan to improve curricular and extracurricular programmes that nurture effective implementation of IM.

\section{Disclosure statement}

No potential conflict of interest was reported by the authors.

\section{Funding}

The funder is the International Baccalaureate Organization.

\section{ORCID}

Jennie Farber Lane (D) http://orcid.org/0000-0002-7763-3813

\section{References}

Akin, S., B. Calik, and C. Engin-Demir. 2017. "Students as Change Agents in the Community: Developing Active Citizenship at Schools." Educational Sciences: Theory and Practice 17 (3): 809-834. doi:10.12738/estp.2017.3.0176.

Bailey, K., and R. Harwood. 2012. "Evaluating and Fostering International-mindedness." International School Journal 15 (2): 18-20.

Bailey, K., and R. Harwood. 2013. "Defining and Evaluating International-mindedness in a School Context." International School Journal 31 (2): 77-86.

Beek, A. E. 2017. Contextual Interpretations of International Mindedness in International Baccalaureate Diploma Programme Students. Bethesda, MD: International Baccalaureate Organization.

Bennett, M. J. 2004. "Becoming Interculturally Competent." In Toward Multiculturalism: A Reader in Multicultural Education, edited by J. S. Wurzel, 66-77. Newton, MA: Intercultural Resource Corporation.

Braun, V., and V. Clarke. 2006. "Using Thematic Analysis in Psychology." Qualitative Research Psychology 3 (2): 77-101. doi:10.1191/1478088706qp063oa.

Brinkman, S., and S. Kvale. 2015. Interviews: Learning the Craft of Qualitative Research Interviewing. Thousand Oaks: SAGE Publications. 
Bunnell, T., M. Fertig, and C. James. 2017. "Establishing the Legitimacy of a School's Claim to Be "International": The Provision of an International Curriculum as the Institutional Primary Task." Educational Review 69 (3): 303-317. doi:10.1080/00131911.2016.1213224.

Castro, P., U. Lundgren, and J. Woodin. 2015. "International-Mindedness through Looking the Glass: Reflections on a Concept." Journal of Research in International Education 14 (3): 187197. doi:10.1177/1475240915614202.

Cause, L. 2009. "Fostering Inclusive and Ethical Intercultural Relations: The IB, InternationalMindedness and the IB Learner Profile." In Paper Presented at the International Conference on Migration, Citizenship and Intercultural Relations, Deakin University, Australia, November 19-20.

Hacking, E., C. Blackmore, K. Bullock, T. Bunnell, M. Donnelly, and S. Martin. 2017. The International-Mindedness Journey: School Practices for Developing and Assessing International-Mindedness across the IB Continuum. Bethesda, MD: International Baccalaureate Organization.

Hammer, M. 2017. “Education Group Profile Report.” Intercultural Development Inventory v.3 (IDI), USA.

Hammer, M., M. J. Bennett, and R. Wiseman. 2003. "Measuring Intercultural Sensitivity: The Intercultural Development Inventory.” International Journal of InterculturalRelations 27 (4): 421-443.

Hansen, C. B. 2011. “Achieving as an Urban School with a Global Vision: One School's Journey to Become Internationally-Minded.” International Journal of Learning 18 (1): 99-110.

Hicks, D. 2003. "Thirty Years of Global Education: A Reminder of Key Principles and Precedents." Educational Review 55 (3): 265-275. doi:10.1080/0013191032000118929.

Hill, I. 2012. "Evolution of Education for International Mindedness." Journal of Research in International Education 11 (3): 245-261. doi:10.1177/1475240912461990.

Hinrichs, J. 2003. "A Comparison of Levels of International Understanding among Students of the International Baccalaureate Diploma and Advanced Placement Programs in the USA." Journal of Research in International Education 2 (3): 331-348. doi:10.1177/ 1475240903002003005.

International Baccalaureate Organization. 2008a. IB Learner Profile Booklet. Cardiff, Wales: Author.

Marshall, H. 2007. "The Global Education Terminology Debate: Exploring Some of the Issues." In The SAGE Handbook of Research in International Education, edited by M. Hayden, J. Levy, and J. Thompson, 38-50. London: SAGE Publications.

Morais, D., and A. Ogden. 2010. "Initial Development and Validation of the Global Citizenship Scale." Journal of Studies in International Education 15 (5): 445-466. doi:10.1177/ 1028315310375308.

Özakman, T. 2017. "An exploratory study of a student-centred course in International Baccalaureate Diploma Programme schools: How is Theory of Knowledge implemented to support intercultural sensitivity?" MA thesis, Bilkent University.

Paige, R. M., M. Jacobs-Cassuto, Y. Yershova, and J. DeJaeghere. 2003. “Assessing Intercultural Sensitivity: An Empirical Analysis of the Hammer and Bennett Intercultural Development Inventory." International Journal of Intercultural Relations 27 (4): 467-486. doi:10.1016/ S0147-1767(03)00034-8.

Schweisfurth, M. 2006. "Education for Global Citizenship: Teacher Agency and Curricular Structure in Ontario Schools." Educational Review 58 (1): 41-50. doi:10.1080/ 00131910500352648.

Singh, M., and J. Qi. 2013. 21st Century International-Mindedness: An Exploratory Study of Its Conceptualization and Assessment. The Hague: International Baccalaureate Organization.

Skelton, M., A. Wigdford, P. Harper, and G. Reeves. 2002. "Beyond Foods, Festivals and Flags." Educational Leadership 60 (2): 52-55.

Sriprakash, A., M. Singh, and Q. Jing. 2014. A Comparative Study of International- Mindedness in the IB Diploma Programme in Australia, China and India. Bethesda, MD: International Baccalaureate Organization. 
Swetz, J., and M. Swetz. 2014. "How Do We Know We are Internationally Minded in a National School?" In Presented at the IB Africa, Europe, Middle East Regional Conference, Rome, Italy, October 16-19.

Tarc, P., and L. Beatty. 2012. "The Emergence of the International Baccalaureate Diploma in Ontario: Diffusion, Pilot Study and Prospective Research." Canadian Journal of Education 35 (4): 341-375.

Yazgan, E. 2017. “The Effectiveness of Creativity, Activity, Service Professional Development in Turkey.” MA thesis, Bilkent University.

Yin, R. K. 2003. Case Study Research: Design and Methods. Thousand Oaks: Sage Publications. 